\title{
Bartolomé de las CASAS: Brevísima relación de la destruición de las Indias. (Edición, estudio y notas de José Miguel Martínez Torrejón)
}

Barcelona: Galaxia Gutemberg-Círculo de Lectores (Biblioteca Clásica de la Real Academia Española, 28), 2013 (1 $1^{\mathrm{a}}$ ed.), XII, 364 pp.; 21 cm. ISBN: 978-84-1586301-4.

Todo un clásico de nuevo en nuestras manos, en una cuidada edición crítica de José Miguel Martínez Torrejón a partir de la primera edición de 1552, cotejándola con la de 1646 y los manuscritos llegados hasta nosotros. El trabajo de Martínez Torrejón va mucho más allá de fijar el texto, con el oportuno aparato crítico y una batería de notas que demuestran su dominio de la vasta bibliografía lascasiana; nos ofrece, además, un interesante estudio introductorio que permite calibrar la importancia y los avatares por las que ha atravesado la obra del considerado «apóstol de los indios». Es una tarea difícil y llena de trampas, resuelta con ecuanimidad, pues la obra de Las Casas, huelga recordarlo, fue una obra de batalla, quizá una de las obras que más polémica levantaron cuando fueron publicadas de entre las que han salida de las prensas de nuestro país. Pero, a diferencia de otras, ésta sigue estando en el ojo del huracán, siendo más citada que leída, y el obispo de Chiapas es aún hoy tan ensalzado como vituperado más allá de cualquier valoración crítica.

Ahora bien, nunca se puede decir de una edición que sea la definitiva, por muy alto que se ponga el listón, y un ejemplo de ello es la trayectoria seguida en los últimos años por la que nos ocupa. Puede sorprender este aserto cuando hablamos de una primera edición, como así consta en su última página y en las fichas catalográficas que en ella se inspiran, pero es que esta referencia lleva al equívoco y se encuentra frontalmente con la que aparece, casi de forma subrepticia -porque hace falta una lectura detenida para darse cuenta de ello- tras el apartado de agradecimientos, donde aparece una «Nota a la tercera edición». En esta nota se habla de que en la tercera edición se ha alterado «sólo ocasionalmente» la puntuación y de «algunas modificaciones» en las notas; pero en ningún momento se identifican las anteriores ediciones, que se puede considerar que son tres y no dos, por lo que sería la cuarta la que ahora comentamos.

He localizado en las bibliotecas otras dos ediciones impresas anteriores de la Brevísima de Las Casas, debidas ambas a Martínez Torrejón: la «princeps» de 2006, publicada por la Universidad de Alicante, y otra de 2009, en Galaxia Gutemberg, que 
no he tenido oportunidad de consultar; a ellas habría que añadir la edición electrónica que está disponible en la Biblioteca Virtual Miguel de Cervantes, asimismo realizada por Martínez Torrejón.

Comparando la edición de Alicante y la que comentamos las diferencias no parecen significativas. Aparte de alterar el orden seguido en la primera entre el texto de Las Casas y el análisis de Martínez Torrejón, el «Estudio introductorio» de 2006 se convierte en «Fray Bartolomé de Las Casas y la Brevísima relación» en 2013, numerando epígrafes antes sin numerar y creando dos nuevos ( 7 y 8) que sólo añaden el título sin modificar un ápice el contenido; en 2006 se sangraban los textos introducidos y en 2013 no; en 2013 hay unas pocas notas añadidas, desaparece alguna y se modifican otras más. También la extensa bibliografía se actualiza oportunamente con los títulos aparecidos después de la primera edición. Las modificaciones llegan a los agradecimientos, que se acumulan, y entre ellos una referencia a que «a la magnanimidad del mismo Servicio de Publicaciones de la Universidad de Alicante agradezco que esta segunda (sic) edición salga en la Biblioteca Clásica».

No voy a insistir en una engorrosa relación de las pequeñas diferencias existentes entre las sucesivas ediciones ni pretendo identificar, quizás de forma forzada, una evolución en los planteamientos del editor, que no la hay o no me resulta evidente. Son pequeños matices que sólo sabrá apreciar el lector muy especialista en la obra de Las Casas.

Primitivo J. Pla Alberola

Universidad de Alicante 